\title{
O gerenciamento de riscos nos projetos turísticos: o caso do Projeto de Turismo Solidário no distrito do Frade - Macaé (Rio de Janeiro/RJ, Brasil)
}

\author{
The risk management in tourism projects: the case of Solidary Tourism Project in \\ Frade District - Macaé (Rio de Janeiro/RJ, Brazil)
}

\author{
Juliana Ribeiro Tomaz da Silva Nunes (NUNES, J. R. T. S.) ${ }^{*}$
}

\begin{abstract}
RESUMO - O desenvolvimento da atividade turística em uma localidade transforma seu espaço em um território turístico, no qual muitas relações de poder se fazem presentes. Compreender qual é o grau de influência do gerenciamento de riscos para a tomada de decisão quanto a implementação de um projeto turístico é fundamental, já que uma gama de stakeholders e variáveis estão envolvidas. Quanto aos procedimentos metodológicos, a presente pesquisa se constitui de uma abordagem qualitativa e descritiva, na qual se buscou analisar e correlacionar de modo particular, os impactos da gestão de riscos para projetos turísticos que envolvem a transformação do território, a partir do Estudo de Caso do projeto "Turismo Solidário Frade Macaé" (Rio de Janeiro/RJ, Brasil) que começou a ser planejado no ano de 2016. Além disso, utilizou-se a pesquisa bibliográfica e documental, empregando técnicas como observação participante. Como principal resultado, destaca-se que o gerenciamento de riscos teve uma ação singular para a tomada de decisão em relação a adiar a implementação do "Projeto de Turismo Solidário no Frade", já que o contexto político não era favorável e a comunidade local ainda não estava preparada para receber as ações, que despenderiam recurso, tempo e orçamento em vão para a época em que seria implementado.
\end{abstract}

Palavras-Chave: Turismo; Projeto; Gerenciamento de Risco; Turismo Solidário; Macaé - RJ.

ABSTRACT - The development of tourism in a locality transforms their space into a tourist territory, where many relations power are present. Understand what is the degree of influence of the risk management for decision making regarding the implementation of a tourism project is critical, since a range of stakeholders and variables are involved. As for the methodological procedures, this research constitutes a qualitative and descriptive approach, which seeks to analyze and correlate in particular, the impact of the risk management for tourism projects involving the transformation of the territory, from the Case Study project "Solidary Tourism in Frade - Macaé."( Rio de Janeiro-RJ/Brasil). In addition, we used bibliographic and documentary research, using techniques such as participant observation. The main result, it is emphasized that risk management had a singular action for decision making in relation to postpone the implementation of "Solidary Tourism Project in Frade," as the political context was not favorable and the local community still was not prepared to receive the actions, which naturally spend resource, time and budget to go to the time that would be implemented.

Key words: Tourism; Project; Risk management; Solidary Tourism; Macaé - RJ.

\footnotetext{
*Formação: Graduação em Turismo (Bacharelado) pela Universidade Federal de Minas Gerais (UFMG) e MBA em Gestão de Projetos na Universidade Estácio de Sá. Atividade profissional: Atuou como Gerente Executiva do Macaé Convention \& Visitors Bureau de Macaé e atualmente compõe a equipe técnica de turismo da Subsecretaria de Turismo de Macaé. Endereço físico para correspondência: Av. Presidente Sodré, 534, $4^{\circ}$ andar (Centro). CEP: 27913-080 - Macaé - Rio de Janeiro/RJ - Brasil. E-mail: julianaribeirots@gmail.com
} 


\section{INTRODUÇÃO}

O turismo, ao longo dos anos, vem ganhando espaço na cadeia produtiva de diversas cidades do Brasil e do mundo. Projetos turísticos vêm sendo desenvolvidos a fim de criar novos produtos turísticos e que por sua vez implicam em modificações no espaço onde se dá o desenvolvimento da atividade do turismo.

Qualquer novo produto turístico que seja concebido trará com ele a criação ou o aperfeiçoamento de equipamentos turísticos e da infraestrutura da localidade em questão. Diversos atores locais compõem a cadeia produtiva a ser formada e com ela o conjunto de interesses dos stakeholders ${ }^{1}$ devem ser gerenciados e equilibrados a fim de que o sucesso da atividade desempenhada possa acontecer.

Nesse contexto, as ferramentas do gerenciamento de risco podem assumir um papel decisivo no desenvolvimento de um projeto, tendo a presente pesquisa nascida da inquietude de observar qual seria o grau de influência do gerenciamento de riscos para a tomada de decisão quanto à implementação de um projeto turístico.

As variáveis que podem impactar um projeto de formatação de novos produtos turísticos são inúmeras e o grande número de stakeholders, com seus diferentes interesses e suas diversificadas atividades, podem ser fontes de riscos significativos para o desenvolvimento das ações de projetos turísticos, justificando a compreensão do grau de influência do gerenciamento de riscos na implementação dos mesmos.

A cidade de Macaé, recorte dessa pesquisa, vem, sobretudo, desde o ano de 2015, dando passos importantes na estruturação e formatação de produtos no segmento de lazer, ecoturismo e aventura. O município, com a recente crise econômica e política que o Brasil vem atravessando desde 2014 somada à crise do Petróleo, que impacta diretamente a cidade - que tinha a sua cadeia produtiva totalmente voltada para o setor de Petróleo e Gás - se viu em uma fase desfavorável e vem fazendo da crise uma oportunidade para se reinventar.

Diante desse cenário, o turismo de lazer vem sendo analisado e, aos poucos, formatado para que a atividade seja uma das alternativas à economia da cidade. ( $O$

\footnotetext{
${ }^{1}$ Stakeholder é uma pessoa ou um grupo que possui participação e/ou interesse em um determinado negócio ou empresa. Stakeholders também podem significar partes interessadas, sendo pessoas ou organizações que podem afetar e serem afetados pelos projetos da empresa. Adaptado de Portal da Administração. Disponível em: <http://www.portal-administracao.com/2014/07/stakeholders-significadoclassificacao.html>. Acesso em: 05/02/2017.
} 
DEBATEON, 2016²). Nesse contexto, surgiu o "Projeto Turismo Solidário Frade/Macaé", elaborado pela equipe técnica da Subsecretaria de Turismo de Macaé no início do ano 2016, formada por turismólogos com especializações em diferentes áreas como o Marketing Turístico, Gestão de Projetos e Docência do Ensino Superior.

O projeto nasceu após o diagnosticar, a partir dos dados internos do Inventário Turístico de Macaé (2016), que os equipamentos turísticos estavam concentrados somente em um dos distritos da serra, o Sana. Constatou-se então, que diante do grande potencial turístico presente na serra macaense (INVENTÁRIO TURÍSTICO DE MACAÉ, $2016^{3}$ ) o projeto teria como finalidade diversificar a oferta turística, de modo a expandir os meios de hospedagem na região serrana, proporcionando a geração de novos empregos, o aumento da renda e a oportunidade do turista vivenciar os costumes e estar mais em contato com a comunidade local. (DADOS INTERNOS DO PROJETO TURISMO SOLIDÁRIO - FRADE/RJ, 2016).

Assim sendo, tendo como objetivo geral investigar de modo mais profundo a relação entre projetos turísticos e gerenciamento de riscos, elaborou-se a seguinte problemática: Como o gerenciamento de risco estaria sendo utilizado para a implementação do Projeto de Turismo Solidário no Distrito do Frade/Macaé-RJ? Acreditava-se que o Poder Público do Turismo de Macaé estivesse utilizando o gerenciamento de riscos como uma ferramenta de grande importância para a tomada de decisão referente às ações de implementação do "Projeto de Turismo Solidário no distrito do Frade - Macaé/RJ".

Desse modo, três dos objetivos da presente pesquisa foram também observar como se deu a incorporação de ferramentas de gestão de risco na etapa de planejamento de um projeto do âmbito público, além de apresentar as vantagens da gestão de risco na avaliação do projeto "Turismo Solidário no Frade" - Macaé/ RJ. Se fez necessário, também, demonstrar como a gestão de riscos poderia minimizar ou evitar esforços desnecessários com a implantação de um projeto turístico de alto risco.

Quanto aos procedimentos metodológicos, na pesquisa se fez uso da abordagem qualitativa e descritiva, uma vez que se desejou compreender, analisar e correlacionar,

\footnotetext{
${ }^{2}$ ODEBATEON. Ponto de Vista. Disponível em:

<http://www.odebateon.com.br/site/blog/artigo/1062/mais-um-ano>. Acesso em: 15/02/2016.

${ }^{3}$ Os dados do Inventário Turístico de Macaé estão disponíveis para consulta interna ou na versão digital, não tendo ainda uma versão online.
} 
de modo particular, os impactos da gestão de riscos para projetos turísticos territoriais, a partir do Estudo de Caso do projeto "Turismo Solidário no distrito do Frade - Macaé", buscando uma observação e investigação dos aspectos particulares desse caso.

Com a finalidade de alinhar o pensamento científico com as observações a serem feitas na pesquisa, foram utilizados como procedimentos técnicos a "Pesquisa Bibliográfica" e a "Pesquisa documental", buscando nos documentos informações sobre o distrito do Frade e a respeito do projeto Turismo Solidário. Em relação as técnicas e instrumentos para a coleta de dados, a observação participante foi a principal ferramenta para análise do Estudo de Caso. A escolha dessa especificidade se deu pela autora em questão participar da situação observada, sendo desse modo uma componente do projeto estudado.

\section{PROJETOS TURÍSTICOS: UMA TRANSFORMAÇÃO TERRITORIAL}

De acordo com PMI (2013, p. 3) "Projeto é um esforço temporário empreendido para criar um produto, serviço ou resultado único" e o resultado do projeto pode ser tangível ou intangível.

Nessa mesma linha de pensamento encontrada no Guia PMBOK, Carvalho Junior (2012) apresenta que um projeto tem como objetivo o alcance de um desejo, de uma ideia ou de algum objeto material, reforçando o pensamento de que o resultado de um projeto pode ser tangível ou intangível.

Se tratando do gerenciamento de projetos, PMI (2013, p. 5) revela, a seguir, os seus cinco grupos de processos, nos quais são aplicadas as técnicas e habilidades para se atender os requisitos de um projeto:

[...] é a aplicação do conhecimento, habilidades, ferramentas e técnicas às atividades do projeto para atender aos seus requisitos. $\mathrm{O}$ gerenciamento de projetos é realizado através da aplicação e integração apropriadas dos 47 processos de projetos, logicamente agrupados em cinco grupos de processos. Esses cinco grupos de processos são: iniciação, planejamento, execução, monitoramento e controle e encerramento.

Os 47 processos de gerenciamento são também reunidos em 10 áreas de conhecimento diferenciadas. (PMI, 2013). Essas áreas de conhecimento são um conjunto completo de conceitos e atividades que compõem um campo de gerenciamento 
de projetos, um campo profissional ou uma área de especialização, sendo elas: integração, escopo, tempo, custos, qualidade, recursos humanos, comunicações, riscos, aquisições, partes interessadas.

Pensando em um destino que deseja ter o turismo como parte de sua cadeia produtiva, tendo como resultado final de um projeto a formatação de produtos turísticos, despertando e incentivando as suas vocações turísticas, é possível afirmar que os projetos inerentes a essa formatação proporcionarão uma transformação no espaço físico daquela localidade.

Desse modo, é importante compreender a diferença entre território e espaço, pois segundo Raffestin (1993), o espaço é anterior ao território e o território que se gera a partir do espaço é consequência de uma ação desenvolvida por um ator em qualquer patamar. Desse modo, quando se toma um espaço, concreta ou abstratamente, o ator territorializa o mesmo. Ele afirma também que um espaço onde há uma projeção de um trabalho apresenta as relações marcadas pelo poder, sendo o território nada mais que o produto dos atores sociais. Destarte, o processo de formação de um território se desenvolve quando há a manifestação de todas as espécies de poder, no qual são inseparáveis as relações de interesse e domínio.

Na mesma linha de pensamento de Raffestin, Saquet (2003, p. 24) apresenta que:

O território se dá quando se manifesta e exerce-se qualquer tipo de poder, de relações sociais. São as relações que dão o concreto ao abstrato, são as relações que consubstanciam o poder. Toda relação social, econômica, política e cultural é marcada pelo poder, porque são relações que os homens mantêm entre si nos diferentes conflitos diários.

Para Milton $\operatorname{Santos}^{4}$ (2000, apud CANDEIAS, 2005) o território é muito mais que a somatória do sistema natural com as criações humanas, incorporando também a população, a identidade e o sentimento de pertencimento, sendo um lugar para trocas materiais e imateriais utilizado por uma comunidade de pessoas.

Se tratando da atividade turística, Ashworth ${ }^{5}$ em 1989, foi um dos primeiros pesquisadores que identificou a cidade como um cenário significante para a atividade

\footnotetext{
${ }^{4}$ SANTOS, M. Por uma outra globalização: do pensamento único à consciência universal. Rio de Janeiro: Record, 2000.

5 ASHWORTH, G. J. Urban Tourism: an imbalance in attention. In: COOPER, C. P. (ed.), Progress in tourism recreation and hospitality management, v. 1, p. 33-34. London: Belhaven, 1989.
} 
turística, já que nela acontece o uso de espaços específicos para as experiências dos visitantes (HAYLLAR, 2011). Desse modo, é fundamental compreender como o turismo se apropria de um espaço, dando-lhe também uma possível identidade turística.

Se faz necessário também tomar conhecimento de quais aspectos envolvem o conceito de turismo. Segundo a definição da Organização Mundial de Turismo, OMT (2001), o turismo acontece quando ocorre o deslocamento do homem no espaço, longe do seu local de residência, por um período mínimo de 24 horas e em um período máximo de um ano, tendo como principais fins o lazer, negócios entre outros.

Partindo do pensamento citado anteriormente, em que o território se forma a partir do uso do poder e das relações sociais, ao se usar um espaço para a formatação de produtos turísticos e para o desenvolvimento da atividade turística, relações de interesse e poder se manifestam nesse espaço, uma vez que o setor gera uma enorme cadeia produtiva de serviços que podem modificar a economia, o lado social, cultural e político da localidade.

Essa transformação ocasionada pelo turismo, uma vez bem trabalhada, poderá alavancar o crescimento do destino em que suas atividades estão sendo desenvolvidas. De acordo com Alves (2010), o turismo se configura como uma nova visão estratégica de desenvolvimento, com reais possibilidades de elevar ao máximo as potencialidades locais, sendo necessário apenas que essas estratégias sejam hábeis de aproveitar esse fenômeno de modo a impulsionar o crescimento econômico para toda a sociedade.

Portanto, é possível afirmar que para o desenvolvimento do turismo, o espaço é modificado para a formatação de um produto turístico, e este por sua vez é constituído, segundo Ministério do Turismo (2007), pelos atrativos da localidade, os equipamentos turísticos e a infraestrutura local acrescidos de facilidades, situados em um ou mais municípios e oferecido de modo organizado por um determinado preço.

Dias e Cassar (2005) afirmam que quando se oferece ao mercado um produto bens ou serviços - estão oferecendo meios para satisfazer as necessidades do consumidor. Eles afirmam ainda que:

Desse modo, o conceito de produto torna-se amplo e não se encerra no bem ou serviço. Esses, na realidade, constituem um aspecto do produto ou, dito de outro modo, constituem apenas um nível de produto, já que existem outros níveis que englobam sua comercialização, tais como o meio ambiente físico e cultural e as interações necessárias para obter o produto. (DIAS; CASSAR, 2005, p. 184). 
Especificando o conceito de produto, para produto turístico, Dias e Cassar (2005) apresentam que ele é o conjunto de elementos ou ações desempenhadas e destinadas a satisfazer à satisfação das necessidades do turista:

\begin{abstract}
Assim, o transporte, um hotel, um restaurante, um atrativo, uma paisagem, todos podem ser considerados como produtos em si, que agrupados, constituem o produto turístico que pode ser adquirido na forma de pacote, visualizado pelo cliente-turista. (DIAS; CASSAR, 2005, p. 184).
\end{abstract}

Destaca-se também a importância de se conhecer as características singulares inerentes aos produtos turísticos. Segundo Dominguez ${ }^{6}$ (2001 apud DIAS; CASSAR 2005) os produtos turísticos não podem ser armazenados, devendo ser consumidos no próprio local, já que a produção e o consumo são gerados de forma simultânea; o bem turístico se adapta lentamente às variações da demanda; o produto global é formado por diversos subprodutos. Outra característica importante é que produto turístico é intangível e não se podendo possuir ou trocar um produto turístico, mas simplesmente usufruí-lo.

Destarte, os projetos turísticos que têm como objetivo a criação de novos produtos turísticos modificam um espaço para o desenvolvimento da atividade turística. Qualquer novo produto turístico que seja concebido trará com ele a criação ou o aperfeiçoamento de equipamentos turísticos e da infraestrutura da localidade em questão.

\title{
3 O GERENCIAMENTO DE RISCOS E A IMPORTÂNCIA DO PROCESSO DE PLANEJAMENTO: UM DIFERENCIAL PARA A IMPLEMENTAÇÃO DE UM PROJETO TURÍSTICO
}

Como foi apresentado anteriormente, a gestão de riscos faz parte das 10 áreas de conhecimento definida por PMI (2013) e compõe o objeto de estudo da presente pesquisa.

O risco do projeto é um evento ou situação incerta que caso aconteça, acarretará uma consequiência positiva ou negativa em um ou mais objetivos do projeto. (PMI,

\footnotetext{
${ }^{6}$ DOMINGUEZ, M. Competitividade e Análise Estratéxica do Sector Turístico: Uña Primeira Aproximación á Potential Creación dun Cluster Institucional para a Mellora Competitiva da Zona Rías Baixas", Tese de doutorado, Universidade de Santiago de Compostela, Espanha, 2001.
} 
2013). A origem do risco do projeto está na incerteza existente em todos os projetos, podendo ser classificados como conhecidos, possibilitando o planejamento de respostas e os desconhecidos, que não podem ser gerenciados antecipadamente, podendo ganhar uma reserva de gerenciamento. (PMI, 2013)

Segundo Valeriano (2005), a gestão de riscos consiste em um conjunto de processos sistemáticos de identificação, de análise e avaliação dos riscos e na formatação de respostas apropriadas aos mesmos. Dentro desse mesmo critério, no PMI (2013, p. 309) se apresenta o gerenciamento de riscos do projeto como aquele que:

[...] inclui os processos de planejamento, identificação, análise, planejamento de respostas e controle de riscos de um projeto. Os objetivos do gerenciamento dos riscos do projeto são aumentar a probabilidade e o impacto dos eventos positivos e reduzir a probabilidade e o impacto dos eventos negativos no projeto.

É importante compreender quais as principais atividades dentro dos processos de gerenciamento de risco. De acordo com PMI (2013), o processo "Planejar o gerenciamento dos riscos" orienta como as ações de gerenciamento dos riscos vão acontecer no projeto. O processo seguinte, "Identificar os riscos", define dos riscos que podem comprometer o projeto e documenta suas peculiaridades.

Já os processos "Realizar a análise de qualidade dos riscos" e "Realizar a análise quantitativa dos riscos" priorizam riscos para análise e para atos posteriores por meio da avaliação e associação de sua probabilidade de ocorrência e impacto e avaliam numericamente o efeito dos riscos identificados, respectivamente (PMI, 2013).

O processo posterior, "Planejar as respostas aos riscos", cria opções e ações para maximizar as oportunidades e minimizar os objetivos do projeto. (PMI, 2013). Já o processo "controlar os riscos" avalia a eficácia do processo gerenciamento de riscos e ocorre durante todo o projeto. (PMI, 2013).

Ressalta-se, segundo Vargas (2005), que um projeto para ser bem sucedido deve ser concluído dentro do tempo e orçamento previstos, ter utilizado os recursos sem desperdício, ter atingindo a qualidade e o desempenho almejado, ter sido finalizado com o mínimo possível de modificações no seu escopo, ter sido colocado em prática sem que ocorresse suspensão nas atividades da organização e sem ter violado a cultura da instituição. 
Analisando a atividade turística e, sobretudo as características do produto turístico apresentadas anteriormente, é fundamental realizar de modo correto o planejamento da atividade e a ordenação da mesma em um território. Sem um planejamento correto, os riscos relacionados com a atividade podem levar um destino a se saturar de modo veloz, além de impactar negativamente a vida da comunidade local, como o uso exacerbado da infraestrutura local. Desse modo, Teles (2006, p. 48) afirma que:

O planejamento na atividade do turismo especialmente nos países periféricos, é vital, pois não se pode deixar de considerar que existe uma fragmentação causada pela ordem econômica global que também se faz presente no que se relaciona ao turismo, assim como se faz com relação a qualquer outra atividade econômica.

Ruschmann e Solha (2006) observam também que o planejamento turístico envolve reflexões ligadas à responsabilidade social, ao uso do espaço e do território pelo turismo, às singularidades no desenvolvimento dos planejadores turísticos e das características e dos aspectos da política de turismo.

A importância do planejamento é ressaltada por Heldman (2005), que apresenta quatro zonas distintas de prioridades existentes no mercado a serem administradas por um gerente de projeto sendo elas a "Zona de Combate a Incêndio", a "Zona de Planejamento", a "Zona de desperdício de Tempo" e a "Zona de procurar um novo emprego".

Para a presente pesquisa foram levados em conta os conceitos de duas delas. A primeira é a "Zona de Combate a Incêndio", na qual quando se tem um problema é preciso resolvê-lo na hora, uma vez que os mesmos podem ficar ainda maiores. É necessário abandonar todas as atividades em execução para resolver os problemas que surgem. Para se evitar estar nessa zona, é necessário dedicar mais tempo na "Zona de planejamento". A "Zona de Planejamento" por sua vez é uma zona dinâmica, na qual as prioridades mudam constantemente, tendo como objetivo controlar melhor as atividades, e por sua vez se distanciar da "zona de combate a incêndio" (HELDMAN, 2005). 


\section{O TURISMO SOLIDÁRIO E O TURISMO DE BASE COMUNITÁRIA: UMA ALTERNATIVA À ECONOMIA LOCAL}

É importante compreender o contexto em que surgiu a economia solidária e observar seus fundamentos, para então se compreender as bases do turismo solidário. Segundo Candeias (2005), nos anos 90 houve o empobrecimento da população brasileira e o aumento do índice de desemprego, tendo a economia solidária surgido de modo mais forte e como uma alternativa para os setores populares, a partir do desenvolvimento local.

De acordo com Singer (2003), a economia solidária se refere à organização de produtores, prestadores de serviços, consumidores, entre outros, que têm seu relacionamento baseado nos princípios igualitários e democráticos da autogestão, proporcionando a solidariedade e a integridade entre os componentes da organização e de todos os demais abarcados no sistema produtivo.

Aprofundando-se no âmbito da atividade turística, a maioria dos destinos trabalha o turismo de massa, que não atende a necessidade de fuga do estresse, já que essas localidades atraem cada vez mais um número grande de pessoas. Movimentos de resistência com intuito de valorizar a diversidade cultural e salvaguardar as especificidades dos diversos povos, comunidades e culturas regionais vêm sendo desenvolvidos. Desse modo, o turismo de base comunitária busca se contrapor ao turismo massificado buscando a valorização do vinculo entre os ambientes naturais com a cultura de cada lugar. (BURSZTYN; BARTHOLO; DELAMARO, 2009).

Considera-se importante compreender como o Turismo Solidário e o Turismo de Base Comunitária (TBC) caminham juntos e se completam. De acordo com o Programa Turismo Solidário ${ }^{7}$ do Governo de Minas Gerais (2016) - aplicado nas regiões do Vale do Jequitinhonha e Norte de Minas - tem como proposta a valorização da cultura popular, das potencialidades naturais e do jeito de ser da comunidade local:

Os turistas solidários participam do cotidiano das famílias que os hospedam e têm a possibilidade de compartilhar um pouco de seu conhecimento. Possibilitando a troca de conhecimentos e geração de renda às populações locais, o programa significa esperança de vida melhor para centenas de famílias beneficiadas pelo aumento do fluxo turístico e pela participação solidária dos turistas.

\footnotetext{
${ }^{7}$ Disponível em: <http://www.turismosolidario.com.br>. Acesso: 03/02/ 2016.
} 
Já o Turismo de Base Comunitária é apresentado como aquele em que a comunidade local possui o controle efetivo sobre o seu desenvolvimento e gerenciamento, tendo como objetivo a valorização da cultura e aplicação da economia solidária, como apresentado a seguir:

O Turismo de Base comunitária é aquele no qual as populações locais possuem o controle efetivo sobre o seu desenvolvimento e gestão, e está baseado na gestão comunitária ou familiar das infraestruturas e serviços turísticos, no respeito ao meio ambiente, na valorização da cultura local e na economia solidária. (TUCUM ${ }^{8}$ apud SANSOLO; BURSZTYN, 2009, p. 147).

No Brasil, a prática do Turismo Solidário e do TBC é fortalecida por meio da existência da Rede Brasileira de Turismo Solidário e Comunitário - TURISOL ${ }^{9}$ - que surgiu em 2003 com o objetivo de fortificar as práticas do segmento dentro do país. Ela é formada por organizações sendo composta por 9 projetos, presentes em 7 estados do Brasil e 59 municípios.

Contudo, segundo Bursztyn; Bartholo e Delamaro (2009), somente em 2008, o Ministério do Turismo passou a reconhecer as ações de base comunitária e fornecer recursos para o fomento de tais atividades.

\subsection{O PROJETO TURISMO SOLIDÁRIO - FRADE/MACAÉ: O DISTRITO DO FRADE E A CONTEXTUALIZAÇÃO DO PROJETO}

Segundo dados internos do Inventário Turístico de Macaé, $2016^{10}$, Macaé é um município que está localizado a cerca de $200 \mathrm{~km}$ da capital do estado do Rio de Janeiro, Norte Fluminense, região denominada turisticamente como Costa do Sol. A Serra de Macaé é constituída por uma cadeia de montanhas entrecortadas por cachoeiras, rios e vales. São seis distritos no município - Sede, Cachoeiros de Macaé, Córrego do Ouro,

\footnotetext{
${ }^{8}$ A Rede Tucum é uma articulação formada, desde 2008, por grupos de comunidades da zona costeira que realizam o turismo comunitário no Ceará. Disponível em: <http://www.tucum.org/rede-tucum/quemsomos/>. Acesso: 05/02/2017.

${ }^{9}$ Disponível em: <http://www.projetobagagem.org/2009/parceiros.asp?cod=12>. Acesso: 15/02/2016.

${ }^{10}$ Os dados do Inventário Turístico de Macaé estão disponíveis para consulta interna ou na versão digital, não tendo ainda uma versão online.
} 
Glicério, Frade e Sana - que compõem a região que possui grande potencialidade turística. (INVENTÁRIO TURÍSTICO DE MACAÉ, 2016).

Todos os distritos possuem recursos turísticos, contudo, a maior parte dos equipamentos turísticos (meios de hospedagem e gastronomia) da região serrana se concentra no distrito do Sana. Os demais distritos ainda carecem dessa infraestrutura mínima que possa atender às necessidades dos turistas. (INVENTÁRIO TURÍSTICO DE MACAÉ, 2016).

O distrito do Frade, localizado aproximadamente a $56 \mathrm{~km}$ do centro urbano de Macaé, abriga o ponto culminante de Macaé, o Pico do Frade, com 1.429 metros. A exuberância da pedra pode ser visualizada de diversos pontos da cidade e do litoral macaense, sendo no passado um ponto de referência para muitos navegantes. Atualmente, o atrativo proporciona a prática da caminhada e de escaladas. (PREFEITURA DE MACAÉ, 2016). ${ }^{11}$

O distrito do Frade, no século passado, sofreu certa estagnação econômica, em virtude de acontecimentos históricos que implicaram em seu isolamento, como a ausência da estrada de ferro que foi instalada no distrito de Glicério e posteriormente, a carência do asfalto, que só nesse século se viu minimizada. Hoje, o distrito apresenta algumas fazendas de gado e um pequeno comércio sendo formado basicamente de um distrito residencial. (SERRA MACAENSE, 2016) ${ }^{12}$

Como já apresentado anteriormente, Macaé vem buscando se reinventar a partir da crise instalada no município, desde 2014, com as inúmeras demissões em massa, das mais diversas empresas do ramo offshore ${ }^{13}$ (PREFEITURA DE MACAÉ, 2016). ${ }^{14}$

Nesse contexto, o turismo de lazer vem sendo analisado e, aos poucos, formatado para que a atividade seja uma alternativa à economia da cidade.

\footnotetext{
11 Disponível em: <http://www.macae.rj.gov.br/conteudo/leitura/titulo/regiao-serrana>. Acesso em: 23/02/2016.

12 Disponível em: <http://www.serramacaense.com.br/serramacaense/serra/frade.htm>. Acesso em: 23/02/2016.

${ }^{13}$ Empresa que possui a sua contabilidade num país distinto daquele (s) onde exerce a sua atividade.

14 Disponível em: <http://www.macae.rj.gov.br/noticias/leitura/noticia/roteiros-turisticos-apresentampotencialidades-de-macae >. Acesso em: 03/01/2017.
} 
(PREFEITURA DE MACAÉ). ${ }^{15}$ Roteiros turísticos vêm sendo desenvolvidos pelo poder público local em parceria com empresas privadas, a fim de trazer um novo posicionamento de mercado para o município. (PREFEITURA DE MACAÉ, 2016). ${ }^{16}$

Com o grande potencial turístico na serra, e com os equipamentos turísticos concentrados, sobretudo no distrito do Sana, a Subsecretaria de Turismo começou a estudar e analisar a possibilidade de incorporar o Turismo Solidário no Distrito do Frade. (SUBSECRETARIA DE TURISMO DE MACAÉ, 2016). ${ }^{17}$

É importante também compreender o motivo da escolha do Frade pela Subsecretaria de Turismo de Macaé. Primeiramente, como já apresentado, o distrito do Frade possui sua economia voltada para produtores rurais e pequenos comerciantes. Com o intuito de expandir a oferta de Meios de Hospedagem na região serrana, proporcionando a geração de novos empregos, o aumento da renda e a busca por não impactar negativamente a rotina da comunidade local, a Subsecretaria de Turismo de Macaé, no início do ano de 2016, viu no segmento de Turismo Solidário uma possibilidade se encaixar de modo positivo na realidade daquela localidade. (SUBSECRETARIA DE TURISMO DE MACAÉ, 2016). ${ }^{18}$

Além disso, de acordo com o Inventário Turístico de Macaé (2016), o distrito do Frade se localiza próximo ao Sana, que concentra grande parte dos atrativos já formatados da região serrana, de Glicério, que oferece práticas de Canoagem e das empresas que proporcionam a prática do Rafting no Rio Macaé.

\section{ESTUdO DE CASO: O PROJETO TURÍSMO SOLIDÁRIO DO FRADE - MACAÉ/RJ}

Neste tópico se discorre sobre as ações propostas pelo projeto e o uso do gerenciamento de riscos.

\footnotetext{
15 Disponível em: <http://www.macae.rj.gov.br/noticias/leitura/noticia/roteiros-turisticos-apresentampotencialidades-de-macae>. Acesso em: 03/01/2017.

16 Disponível em: <http://www.macae.rj.gov.br/noticias/leitura/noticia/capacitacao-visa-fomentarturismo-de-lazer>. Acesso em: 03/01/2017.

17 Dados constatados a partir da observação participante da pesquisadora inserida no processo de desenvolvimento do projeto.

18 Dados constatados a partir da observação participante da pesquisadora, inserida no processo de desenvolvimento do projeto.
} 


\subsection{AS AÇÕES PROPOSTAS PELO PROJETO TURISMO SOLIDÁRIO FRADE/MACAÉ}

De acordo com a Subsecretaria de Turismo de Macaé (2016), o objetivo do Projeto Turismo Solidário no Frade era sensibilizar, identificar, capacitar e registrar aqueles moradores do distrito que tinham o desejo de fazer de sua moradia um meio de hospedagem, no qual o turista iria conviver com a realidade da família hospedeira e com as atividades rotineiras daquela localidade, além de usufruir das atratividades da região serrana. (PROJETO TURISMO SOLIDÁRIO - FRADE MACAÉ, 2016). ${ }^{19}$

Segundo dados do Projeto Turismo Solidário Frade- Macaé (2016), a primeira ação que seria realizada era a sensibilização da comunidade local, por meio de visitas às casas, conversas, reuniões com membros da associação dos moradores, com o intuito de fazê-los conhecer o projeto e posteriormente aderir a ele. Dado esse primeiro passo, o projeto iria pesquisar os moradores que desejariam fazer parte do projeto, e a partir dessa identificação, um especialista da área visitaria o Frade para compreender o contexto do distrito e auxiliar nas adequações. (DADOS INTERNOS DO PROJETO TURISMO SOLIDÁRIO - FRADE MACAÉ, 2016).

A partir dessas ações, a mobilização da iniciativa privada, dos receptivos locais e das Secretarias e Órgãos municipais seria iniciada. (DADOS INTERNOS DO PROJETO TURISMO SOLIDÁRIO - FRADE MACAÉ, 2016).

De acordo com os dados internos do Projeto Turismo Solidário Frade - Macaé (2016), com todas essas ações alinhadas, o cadastro das propriedades se iniciaria e a capacitação e qualificação dos moradores seria realizada. A formatação dos roteiros e a incorporação dos já existentes, como parte do pacote turístico e de opções para o turista usufruir, começariam a ser desenvolvidos.

A sinalização turística viária e a sinalização indicativa dos meios de hospedagem também começaria a ser formatada. Desse modo, as casas, assim como acontece em outros lugares que já realizam o Turismo Solidário, teriam uma placa de identificação como os dizeres "Turismo Solidário" que também seriam afixadas nas residências pertencentes ao projeto do Frade. (DADOS INTERNOS DO PROJETO TURISMO SOLIDÁRIO - FRADE MACAÉ, 2016).

\footnotetext{
${ }^{19}$ Dados internos disponibilizados pela Subsecretaria de Turismo de Macaé.
} 
Por fim, como apresentado por meio dos dados obtidos do Projeto Turismo Solidário do Frade (2016), o plano de marketing seria colocado em ação, e entre as ações, a criação de um site e a divulgação dos roteiros em agências e locais de público final começariam a ser desenvolvidas.

\subsection{O USO DO GERENCIAMENTO DE RISCOS NO "PROJETO TURISMO SOLIDÁRIO - FRADE/MACAÉ"}

Observando as etapas do gerenciamento de riscos para o Projeto Turismo Solidário no Frade, notou-se que foi dada uma grande importância, despendendo tempo para a fase do planejamento, identificação e análise dos riscos, para então verificar a possibilidade de implementação do projeto no Frade.

Na etapa "Planejar o gerenciamento dos riscos", destacava-se como entrada o registro das partes interessadas do projeto, sendo identificados os principais stakeholders ligados direta e indiretamente ao projeto.

Destaca-se também nessa fase, a análise dos Fatores Ambientais da Empresa, na qual foi feito um estudo sobre as práticas de Turismo de Base Comunitária e Turismo Solidário com intuito de compreender melhor as condições desse mercado e o desempenho de localidades que implantaram tais segmentos.

Desse modo, descobriu-se haver uma ausência de metodologias para implantar de modo correto um projeto de Turismo de Base Comunitária. (MIELKE; PEGAS, 2012). A ineficácia de um ou mais dos processos como acesso ao mercado, governança interna e gestão das parcerias estratégicas de interesse faz com que mais de três quartos dos projetos de TBC sejam frágeis e/ou que a longo prazo não se sustentem. (MIELKE ${ }^{20}, 2009$ apud MIELKE; PEGAS, 2012).

\footnotetext{
${ }^{20}$ MIELKE, E. J. C. Desenvolvimento Turístico de Base Comunitária. Campinas, São Paulo: Átomo \& Alínea, 2009, v. 1. p. 190, 2009.
} 
Já na etapa da "Identificação dos Riscos" se utilizou como ferramenta a opinião especializada, brainstorming entre os turismólogos que compõem a equipe técnica de turismo $^{21}$ e técnicas de diagramas, com o objetivo de esquematizar as fases do projeto e as consequências do sucesso ou não de cada fase. Desse modo, a partir da visualização de cada fase apresentada no fluxograma a seguir é possível observar existirem duas etapas decisivas para o prosseguimento da proposta de implantar o Turismo Solidário. A primeira delas é a "Pesquisa com a população e propriedades rurais" para observar o interesse da comunidade em aderir ao projeto e em segundo a "Mobilização com a iniciativa privada, receptivos e agências, secretarias e órgãos municipais".

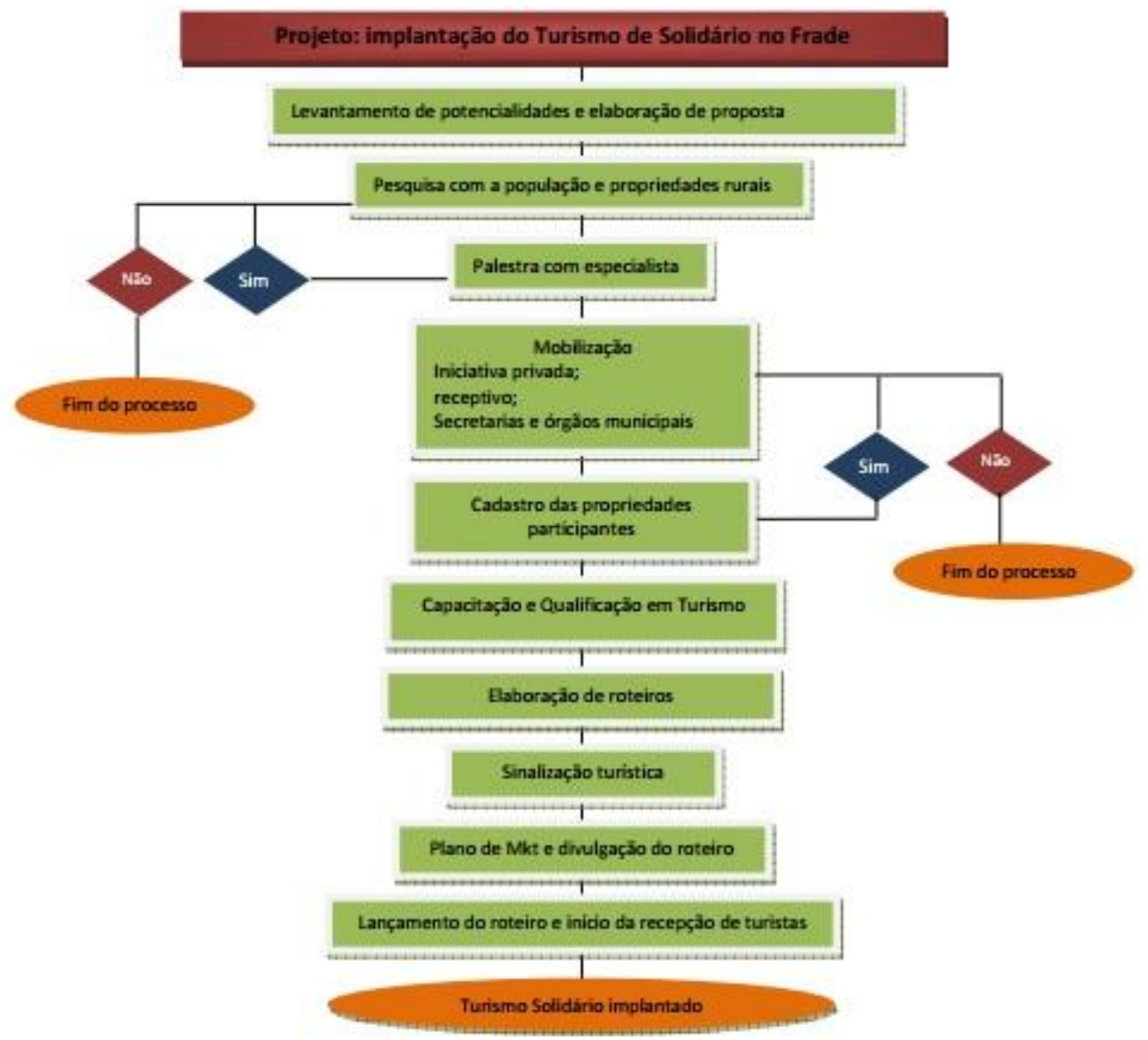

FIGURA 1 - FLUXOGRAMA - IMPLEMENTAÇÃO DO TURISMO SOLIDÁRIO FRADE FONTE: Dados internos do Projeto Turismo Solidário - Frade, 2016.

Ressalta-se também a importância da entrada "Estimativa de duração das atividades" para esse processo, na qual a partir de um cronograma preliminar se revelou

\footnotetext{
${ }^{21}$ Técnica de discussão em grupo que se vale da contribuição espontânea de ideias por parte de todos os participantes, no intuito de resolver algum problema ou de conceber um trabalho criativo.
} 
que a implementação do projeto gastaria cerca de 3 (três) anos. Tendo o início do projeto programado para meados de 2016 - a véspera do ano eleitoral - e seu final um ano após outro mandato, foi considerado uma possível possibilidade de descontinuidade das ações do projeto, caso o mesmo fosse implementado em tal período.

Destarte, a partir da análise de cada etapa do projeto foram identificados os riscos conhecidos do projeto e que serão apresentados a seguir, subdivididos em ameaças (riscos negativos) e oportunidades (riscos positivos), como foi apresentado no quadro 1 - Ameaças e oportunidades - Projeto Turismo Solidário no Frade/Macaé.

\begin{tabular}{|c|c|}
\hline AMEACAS & OPORTUNIDADES \\
\hline $\begin{array}{l}\text { Não aderência da comunidade local; } \\
\text {. Não envolvimento da iniciativa privada; } \\
\text {. Descontinuidade da iniciativa privada; } \\
\text { Descontinuidade política; } \\
\text { O mercado não absorver a oferta; } \\
\text {. Algumas casas receberem turistas, outras não; } \\
\text {. Atores envolvidos não entenderem a importância da qualificação } \\
\text { profissional; } \\
\text { A comunidade não compreender o diferencial do turismo } \\
\text { solidário; } \\
\text { A atividade não gerar a receita desejada para manter os } \\
\text { empreendimentos dos atores locais ligados ao projeto }\end{array}$ & $\begin{array}{l}\text { Valorização da cultura local; } \\
\text { Diferencial competitivo; } \\
\text {. Aumento da renda dos produtores } \\
\text { locais e moradores que aderirem ao } \\
\text { projeto; } \\
\text {. Conservação de biodiversidade - a } \\
\text { partir da visitação das atratividades } \\
\text { da região; } \\
\text {. Diversificar a economia local; }\end{array}$ \\
\hline
\end{tabular}
QUADRO 1 - AMEAÇAS E OPORTUNIDADES - PROJETO TURISMO SOLIDÁRIO FRADE/MACAÉ

FONTE: Dados internos do Projeto Turismo Solidário - Frade, 2016.

Na etapa da "Análise qualitativa dos riscos" foi usada a opinião especializada e avaliação de probabilidade e impacto dos riscos. A probabilidade do risco foi estabelecida a partir de estimação, onde a baixa probabilidade de ocorrência pode ser considerada pequena ou imperceptível; média quando existe uma probabilidade admissível de ocorrência do risco e a alta quando o risco é imediato.

Já os impactos são avaliados como baixos quando o impacto do evento de risco tem mínimas conseqüências para o projeto. Médios quando o impacto do evento de risco possui consequências para o projeto sendo necessário um gerenciamento mais detalhado. E alto quando as consequências do evento de risco são muito grandes podendo comprometer os resultados do projeto. Desse modo os riscos foram avaliados quanto a probabilidade e impacto e são apresentados no quadro a seguir: 


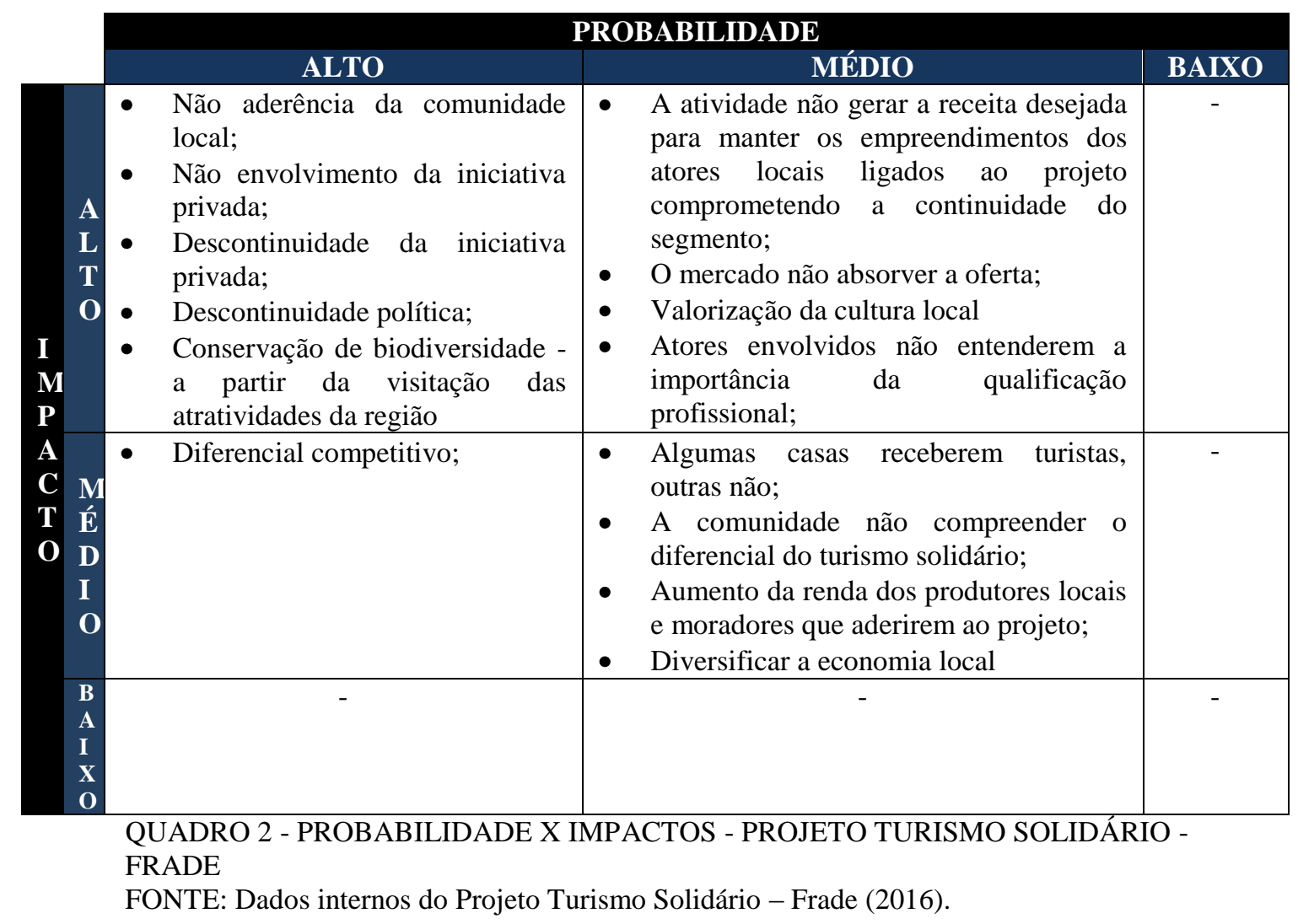

É importante destacar que grande parte dos riscos foram classificados como alto e com grande impacto para o projeto. A não aderência da comunidade local ao turismo solidário inviabilizaria por si só a implementação do mesmo. Esse risco foi classificado como alto pela razão do turismo de lazer ser algo ainda em construção no município de Macaé, podendo não ter despertado, com a intensidade necessária, o olhar da comunidade local a respeito de sua importância e de seus benefícios. Além disso, o turismo de base comunitária e o turismo solidário são movimentos endógenos, ou seja, nascem do desejo da comunidade local em fazer do turismo uma opção para a sua economia e a partir daí as pessoas procurarem as instituições para auxiliar nessa formatação.

O não envolvimento e a possível descontinuidade das ações da iniciativa privada, principalmente dos receptivos locais e as agências de turismo, que iriam trazer o turista para a localidade, se configuraram como um impacto alto para o projeto. Como a cidade vem trabalhando apenas com uma agência que recentemente começou a oferecer serviços de receptivo local, o risco do projeto não ter andamento após ser implantado seria muito alto. 
A descontinuidade política é um fator de suma importância a ser analisado. Como já apresentado, o projeto teria início nas vésperas do ano político e o seu implante um ano após as eleições. Como premissa, pode-se afirmar que muitos projetos, inclusive os do setor do turismo, falham por descontinuidade política. Diante dessa situação, em caso de troca de gestão, as ações de projeto correriam o risco de serem interrompidas.

Um dos riscos positivos, com grande impacto, seria a conservação da biodiversidade, uma vez que o turismo solidário e turismo de base comunitária trabalham com conceitos de sustentabilidade, a partir também da valorização dos costumes da comunidade local e da educação ambiental na visitação dos atrativos.

Outro fator de risco médio, mas de grande impacto, seria a atividade não gerar a receita desejada para manter os empreendimentos dos atores locais ligados ao projeto, comprometendo a continuidade do segmento. No turismo solidário, em geral, as famílias participantes oferecem, em média, um ou dois quartos para hospedar os $\operatorname{turistas}^{22}$. O que ocorre, muitas das vezes, a partir de outras experiências vivenciadas pelos técnicos da Subsecretaria de Turismo de Macaé na região do Vale do Jequitinhonha- MG, é que a família hospedeira opta por fazer algumas reformas na casa visando oferecer mais conforto ao visitante.

Caso o retorno não venha, a continuidade da atividade poderia ser comprometida se houvesse implementação do projeto. Na ocorrência do mercado não conseguir absorver a oferta do Turismo Solidário do Frade, poderia haver uma frustração, em longo prazo, por parte dos atores locais envolvidos e isso poderia gerar um abatimento nos mesmos em continuar nesse segmento turístico, caso o projeto entrasse em vigor.

Outro fator que poderia ter um grande impacto no projeto, comprometendo a qualidade do segmento no Frade, poderia acontecer se os atores envolvidos não entendessem a importância da qualificação profissional. Se os mesmos não absorverem os princípios da boa hospitalidade, poderia haver um comprometimento no feedback ${ }^{23}$ da percepção do visitante em relação ao turismo da localidade.

O projeto poderá atribuir um diferencial competitivo para a localidade, sendo considerado um alto risco positivo, uma vez que os destinos turísticos adjacentes à

\footnotetext{
${ }^{22}$ Observação constatada a partir de outras experiências vivenciadas pelos técnicos da Subsecretaria de Turismo de Macaé na região do Vale do Jequitinhonha- MG.

${ }^{23}$ Informação que o emissor obtém da reação do receptor à sua mensagem, e que serve para avaliar os resultados da transmissão.
} 
Macaé não estavam possuindo esse segmento, podendo o distrito do Frade virar referência na região turística Costa do Sol.

Os demais riscos priorizados e analisados como os riscos negativos (algumas casas receberem turistas, enquanto outras não e a comunidade não compreender o diferencial do turismo solidário), e os riscos positivos (aumento da renda dos produtores locais e dos moradores que aderissem ao projeto e a diversificação da economia local) foram classificados com riscos de médio impacto, podendo gerar consequências para o projeto sendo necessário administrá-los com maior controle.

Concluí-se então, que grande parte dos riscos negativos elencados são riscos altos, com grande probabilidade de ocorrer, alguns devido a fatores estruturais da localidade, que vêm sendo aos poucos trabalhados para serem mitigados e outros relacionados a fatores do mercado, que fogem do controle, e que somados a alguns fatores do contexto atual aumentariam a incerteza da implementação do projeto.

Por fim, observou-se que no processo de "Planejamento da resposta aos riscos" houve uma tentativa de se criar estratégias para maximizar as oportunidades que os riscos positivos trariam e minimizar os efeitos dos riscos negativos. Contudo, alguns riscos, apesar de serem conhecidos, seriam complicados de serem controlados. Entre eles, a descontinuidade da iniciativa privada e a descontinuidade política são fatores que são vulneráveis ao controle e ao monitoramento, sendo difícil atribuir uma ação que minimize seus impactos.

Contudo, observou-se o planejamento de algumas ações para determinados riscos. Por exemplo, a não aderência da comunidade local e a importância dos atores locais receberem qualificação profissional poderia ser gerenciada a partir de uma sensibilização da comunidade com palestras, conversas e brainstormings e, aos poucos, construir o desejo de formatar o turismo solidário com qualidade na localidade. Contudo, se o movimento de aderência dos moradores for totalmente exógeno, ou seja, atores externos à comunidade induzindo a concepção do Turismo Solidário e do TBC, pode fugir da concepção original que confere a característica singular de práticas do Turismo de Base Comunitária. 


\section{CONSIDERAÇÕES FINAIS}

Mediante aos resultados apresentados, observou-se que a gestão de riscos foi decisiva para a tomada de decisão quanto a dar início às ações do projeto Turismo Solidário no Frade. Com o uso de suas ferramentas, foi possível observar que o cenário do período em que o projeto começou a ser planejado não era o mais satisfatório, podendo assim projetar cenários futuros mais favoráveis. Sem o gerenciamento de riscos, o projeto teria sido implementado e o uso de recursos humanos e financeiros para realizar toda a sensibilização e atividades afins seriam desperdiçados, caso o projeto fosse interrompido, se houvesse uma descontinuidade política ou a iniciativa privada não abraçasse as ações e a continuidade do projeto.

Destarte, uma das maiores vantagens de usar o gerenciamento riscos foi observar que diante da exposição do projeto a riscos considerados decisivos e com grande impacto, como a descontinuidade política, somando-se a recente sensibilização da cidade para formatar o turismo, mesmo com riscos avaliados como positivos, percebeuse que a melhor decisão para o momento era adiar a implementação do projeto. Outra vantagem foi observar que adiando a implementação do projeto, um dos riscos mais preocupantes - a descontinuidade política - seria mitigado e os demais já teriam respostas a serem colocadas no plano de contingência. Notou-se também que se a atividade turística conseguisse alcançar a demanda desejada, a partir da oferta que vinha sendo trabalhada na cidade, poderia estimular, de modo espontâneo a comunidade local do Frade a também ter o desejo de desenvolver alguma atividade turística no distrito.

Observou-se que o Poder Público de Turismo de Macaé reconhecia a importância e atribuía um diferencial ao gerenciamento de riscos, fazendo dela uma ferramenta necessária para a avaliação de um projeto. Notou-se também que as diferentes fases do gerenciamento de risco e suas distintas ferramentas foram usadas como apoio na identificação, avaliação e planejamento de respostas aos riscos, para então tomar a decisão final quanto a não implementação do projeto de Turismo Solidário no Frade.

Portanto, devido as peculiares características da atividade turística - como a intangibilidade, heterogeneidade, subjetividade e perenidade do produto turístico - o gerenciamento de riscos exerce um grande auxílio para identificar os riscos, buscando 
maximizar as oportunidades e minimizar as ameaças. Desse modo, dispor de um maior tempo para a identificação e planejamento detalhado das ações de respostas aos riscos é fundamental para reduzir os gastos, gerenciar com eficiência os recursos e o tempo e até mesmo observar se o projeto será viável ou não.

Com intuito de observar a importância e o diferencial da gestão de riscos para projetos turísticos, sugere-se que a continuação de pesquisas que busquem casos de projetos do setor que tiveram sucesso devido ao uso desse gerenciamento, ou que sob o uso das ferramentas de gestão de risco foram adiados com o objetivo de controlar melhor os riscos e observar o momento mais favorável para tal implementação.

\section{REFERÊNCIAS}

ALVES, J. A. B. Arranjo produtivo local e desenvolvimento regional: uma reflexão do APL de Turismo Rota da Amizade (SC, Brasil). Turismo \& Sociedade, Curitiba, v. 3, n. 1, p. 8-36, abril de 2010.

BURSZTYN, I.; BARTHOLO, R.; DELAMARO, M. Turismo para quem? Sobre caminhos de desenvolvimento e alternativas para o turismo no Brasil. In: BARTHOLO, R.; SANSOLO, G. D.; BURSZTYN, I. Turismo de Base Comunitária: diversidades de olhares e experiências brasileiras. Rio de Janeiro: Letra e Imagem, 2009. p. 76-91

CANDEIAS, C. N. B. Economia Solidária, Desenvolvimento Local e Capital Social: a construção de círculos virtuosos. In: CANDEIAS, C. N. B.; MACDONALD, J. B.; NETO, J. F. de M. Economia Solidária e Autogestão - Ponderações Teóricas e Achados Empíricos. Maceió, Alagoas: EDUFAL, 2005. p. 66- 80.

CARVALHO JÚNIOR, M. R. Gestão de projetos: da academia à sociedade. 1. ed. Curitiba: InterSaberes, 2012.

DIAS, R.; CASSAR, M. Fundamentos do Marketing Turístico. 1. ed. São Paulo: Pearson Prentice Hall, 2005.

GOVERNO DE MINAS. Turismo Solidário: o que é? Disponível em: <http://www.turismosolidario.com.br>. Acesso em: 03/02/2016.

HELDMAN, K. Gerência de Projetos: Fundamentos: Um guia prático para quem quer certificação em Gerência de Projetos. Rio de Janeiro: Ed. Elsevier, 2005.

MIELKE; E. J. C.; PEGAS F. V. Turismo de Base Comunitária no Brasil: Insustentabilidade é uma Questão de Gestão. Turismo em análise. Abril, v. 24, n. 1, p. 170-189, 2012. Acesso: 15/02/2016. 
BRASIL, Ministério do Turismo. Programa de Regionalização do Turismo Roteiros do Brasil: Módulo Operacional 8 - Promoção e Apoio à Comercialização. Brasília: Ministério do Turismo, 2007. p. 17.

OMT. Organização Mundial do Turismo. Introdução ao Turismo. São Paulo: Roca, 2001.

PMI, Project Management Institute. Um Guia do Conhecimento Gerenciamento de Projetos (Guia PMBOK). 5. ed. São Paulo: Saraiva, 2013.

RAFFESTIN, C. Por uma geografia do poder. Tradução Maria Cecília França. São Paulo: Ática, 1993.

RUSCHMANN, D.; SOLHA, K. T. Planejamento Turístico. Apresentação. 1. ed. Barueri, SP: Manole, 2006.

SANSOLO, D. G.; BURSZTYN, I. Turismo de base comunitária: potencialidade no espaço rural brasileiro. In: BARTHOLO, R.; SANSOLO, G. D.; BURSZTYN, I. Turismo de Base Comunitária: diversidades de olhares e experiências brasileiras. Rio de Janeiro: Letra e Imagem, 2009.

SAQUET, M. A. Os tempos e os territórios da colonização italiana. Porto Alegre: EST edições, 2003.

SINGER, P. Economia solidária. In: CATTANI, A. D. (Org.). A outra Economia. Porto Alegre: Veraz Editores, 2003. p. 116,

TELES, R. M. de S. A importância do território na prática do planejamento turístico Reflexões acerca do Brasil. In: RUSCHMANN, D.; SOLHA, K. T. Planejamento Turístico. 1. ed. Barueri, SP: Manole, 2006. p. 48,

VALERIANO, D. Moderno gerenciamento de projetos. São Paulo: Prentice Hall, 2005.

VARGAS, R. V. Gerenciamento de projetos: estabelecendo diferenciais competitivos. 6. ed. Rio de Janeiro: Brasport, 2005.

Recebido em: 23-08-2016.

Aprovado em: 23-09-2016. 